\title{
On Progress of Mass Tertiary Education: Case of Lebanon, Kenya and Oman
}

\author{
Zhimin Liu ${ }^{1} \&$ Gladys Mutinda ${ }^{1}$ \\ ${ }^{1}$ Nanjing Agricultural University, Nanjing, China \\ Correspondence: Gladys Mutinda, Nanjing Agricultural University, Nanjing, China. Tel: 86-187-2401-9189. \\ E-mail: gladysmutinda354@gmail.com
}

Received: June 15, 2016

Accepted: July 5, 2016

Online Published: September 6, 2016

doi:10.5539/hes.v6n4p1

URL: http://dx.doi.org/10.5539/hes.v6n4p1

\begin{abstract}
Mass higher education is a huge force to be reckoned with and its existence, already in the expansion of tertiary institutions is undeniable. This study will focus on three countries: Lebanon, Kenya and Oman. The purpose of this study is to evaluate mass tertiary education progress in these countries. It will synthesize data results of gross enrollment ratios, demographics, internationalization and GDP per capita of these countries which we will use as indicators of the progress and direction that mass tertiary education is taking. The principal conclusions of our data will reveal that all 3 countries are experiencing progress only at different rates for varied and different reasons. The findings of this paper are significant as they will aid in informing the governments of the specific countries and other stakeholders who invest in higher education to understand the challenges hindering progress and ensuring that world class academic standards are upheld.
\end{abstract}

Keywords: higher education, mass tertiary education, progress, massification

\section{Introduction}

Chen (2004) argues that the growth of higher education is an all-around, straightforward and consecutively fast, which is probably the reason for it having drawn so much interest and research in the recent past. The mass higher education system is becoming one that is too difficult to ignore and has drawn a lot of interest in the recent world today. Most if not all countries globally are gearing themselves towards mass higher education for their systems and eventually its universalization. The question of whether mass higher education is taking place is not one that is of crucial importance to us at this stage as we can see that mass education is very clearly evident in these countries. It is important at this point, however, to recognize international states that seem to be setting the bar higher as far as massification of higher education is concerned. These states have had clear and very distinct progress as indicated by their gross enrollment ratio rates is quite high as compared to the countries under our scope as we shall see. International developed states that seem to be setting the bar higher as far as massification of higher education is concerned can clearly be seen to surpass the $50 \%$ mark in their enrolment ratios according to the Martin Trow theory which forms the basis of our theoretical framework. These states have had clear and very distinct progress as indicated by their gross enrolment ratio rates which are indicated as in Table 1, which are quite high as compared to the countries under our scope as we shall see.

Table 1. Gross enrollment ratios in Higher Education in various countries in the year 2013

\begin{tabular}{cc}
\hline COUNTRY & GER \% \\
\hline Finland & 91.1 \\
Australia & 86.6 \\
Denmark & 81.2 \\
Austria & 80.4 \\
Russia & 77.9 \\
Italy & 63.5 \\
France & 62.1 \\
Germany & 61.1
\end{tabular}

Source: UIS data. Data extracted on 22 Mar 2016 07:18 UTC (GMT) from UIS. Stat. 
Lebanon, Kenya and Oman are the countries under our scope. These are developing countries and as Chen (2004) notes that mass higher education as a world trend is pushing ahead in developing countries therefore becoming extremely important for us to lower our screening lenses to analyze the progress thus far that these countries have made toward massification. Our focus rather will be to analyze in order to decipher the progress that mass higher education has had thus far in the countries that we have chosen for comparative analysis. Is there notable progress? Is the progress lagging behind? And if so what are the challenges hindering progress? What steps that can be taken to ensure these challenges are properly addressed? The issue of progress is crucial because with expansion of tertiary institutions more and more problems come into play and may hinder an effective and successful expansion of these institutions. To answer these questions, this research synthesizes the data results of 4 key indicators: gross enrollment ratios, demographics, and internationalization/universalization and GDP per capita (economics) through an empirical study.

\section{Significance of Problem and Implication to Theory and Practice}

Most of the research on this topic is mostly on the challenges that mass higher education systems face as they transition through massification. Our research will help narrow down the gap in knowledge on the causes of slug in mass tertiary institutions. This problem is of significant importance so that effective analyses of massification can be carried out, more so to understand if it is contributing effectively to the institutions of higher education. This problem is also equally necessary to address because with expansion come a tad bit too many challenges that if not addressed well can compromise the very function of higher education in these countries. We may ask why higher education? This is because a lot of emphasis is always placed on screening higher education because it is usually seen as a major economic driver in developing countries; it is with this reason therefore we seek to know the progress that tertiary education has had so far to be able to ensure that it stirs economies of these countries towards success. To be able to deal with issues of mass higher education an extensive array of knowledge is required to be able to tackle issues affecting the eventual success of massification. Kinyanjui (2007) notes that to be able deal with higher education, broad needs for knowledge, skills and competence which can be provided through a diversified and differentiated way to give opportunities to increasing number of people needing continuous and lifelong learning. This paper therefore seeks to contribute to the body and knowledge that is needed to deal with issues of expansion even as institutions of higher education gear towards successful massification. Our study contributes highly to higher education in that the findings of this paper will aid in informing the governments of the specific countries and other stakeholders who invest in higher education to understand the challenges hindering progress of massification, issues of quality associated with tertiary institutions and ensuring that world class academic standards are upheld. The findings will aid in providing appropriate solutions and suggestions to the milestones encountered in the progress of massification of the higher education system. The implications of this study on theory and practice is that it provides a clear footing for governments, HEI's other tertiary stakeholders on the problems ailing the successful progress of mass higher education. Understanding these mile storms will enable education providers to better tackle these issues.

Our research strategy includes analysis of academic journal articles and other myriad literatures and case studies to achieve this papers aims and objectives. This research strategy will help shed light in this study as we relate our work to work done previously on this subject. We have employed a comparative strategy in this study as we compare the 3 countries though it is prudent at this point to note that comparative analysis faces challenges as the concept of what should constitute an education system may vary from country to country (Cave \& Weale, 1992). Also, as Claire (1988) states "One may question the usefulness of cross-cultural comparisons because of differences in countries' structures, politics and culture. It is, nevertheless, important to make such comparisons".

\section{Theoretical Framework}

This papers theoretical framework is based on Martin Trow's study on the problems facing transition from Elite to mass higher education in the context of western patterns (see a series studies by Trow, 1969, 1970, 1974, 1979). He acknowledges the fact that any huge or massive transition that is associated with growth will always have ripple effects as in the case of expansive higher education trends. This framework will guide our research as we identify various factors hindering the process of effective progression of massification in the countries under our research lens. These problems are associated with finance, governance and administration, recruitment and selection of students; these are problems that face any transition at it takes from elitism to massification to universalization. Our paper's purpose is to identify the progress that the selected countries are facing so far and what challenges they are facing as they make the transitions according to Trow's theory, we will even be more concerned with why some countries' progress is way below par as compared to others. Our questions will want to find out why the lag in progress and even provide solutions for these countries to be able to play in the same 
level field as far as higher tertiary education is concerned in other countries.

\section{Empirical Literature}

It is only prudent at this point for us to recognize that earlier authors have tackled this issue of massification from various angles, mostly to show how most of the countries were gearing towards massifying their tertiary education. Most of the empirical literatures that we shall analyze in this study will mostly highlight the issues and challenges facing higher education due to its moving towards expansion. Drawing from these literatures, our study therefore seeks to simply add on to the vast knowledge as we seek to analyze the progress thus far of massification. We want to find out the rate of the progress, whether the progress is low or fast towards achieving universalization and if the progress is lagging behind, what are the reasons for this phenomenon and finally how can we ensure that our soaring masses are able to access tertiary education without in any least compromising the academic function of higher education institutions of providing ACADEMIC QUALITY. Boli, Ramirez and Meyer (1985) note that the extensive prevalence of mass education is an extremely striking feature of the modern world today. Education has spread rapidly and extensively in the last 2 centuries, becoming a compulsory and essentially universal institution. Most young people today are motivated towards achieving higher education for both extrinsic and intrinsic benefits that higher education has to offer, this has therefore seen higher education growing extensively with more numbers of people wanting to join these institutions. According to O'Neill, Singh and Donoghue (2004), education has become a commodity in which people seek to invest for their own personal gain thus explaining the recent surges in numbers enrolling for higher education in order to ensure quality of opportunity and as a route to a better life. Higher education plays a crucial role in the development of human resources. One of its main duties is to supply societies with a professional and skilled labor that is specialized to work in jobs that require a high degree of practical and theoretical skills and knowledge. Baporikar and Shah (2012) note that Higher Education Institutions (HEIs) are expanding very fast in Arab countries due to increase in social demand for education and priority of the governments to produce efficient and effective human resources according to the requirements of their economies. Research by Chen (2004) also notes how the process of mass expansion is never smooth and how the widening of access to higher education is substantially the broadening of ideas about higher education. Chen (2004) therefore poses several questions pondering on what higher education is for. Who have the right or privilege to receive a higher education? Who is responsible for the provision of higher education? What is the quality of higher education? These questions posed by Chen are very pertinent as they act as reflectors to what the very core of higher education. Even as our institutions are moving towards exclusive expansion it is important that we do not get lost in expansion while forgetting the very core function of our tertiary institutions. Knowledge therefore has been recognized as a critical and very crucial asset for organizations' that wish to survive in the world market place and that learning is crucial and a dire necessity for new economic conditions as it lays the foundation for knowledge construction (Wesley, 2002) that is why a from time to time evaluation is necessary to understand the rate of progress and if our institutions are serving their function effectively despite going through rapid expansion. Chen also notes that as proof of the extensive massification process in the world, China witnessed a steady and rapid growth in the1990s. The gross enrolment rate went from $3.6 \%$ in 1991 up to $11 \%$ in 2000 , an increase of over 3 times, a prominent signal for the determination to massively expand Chinese higher education. As higher education systems have grown immensely rapidly, close government control has tended to hamper the improvement of quality and the ability of public universities to respond flexibly to evolving economic and social needs (World Bank, 2012b). The screening on higher education is very crucial and critical as among advanced countries, the education levels of their populations are the single most important factor in determining their economic performance (Hanushek \& Welch, 2006; Hanushek \& Woessmann, 2008) and this screening can also be extended to developing countries as well. Amongst middle-income and low-income countries those economies that have high education levels can be seen to enjoy massive welfare benefits (Fasih, 2008; Patrinos \& Psacharopoulos, 2011). It is further indicated that the demand for higher education is expanding exponentially throughout the world and by 2025 as many as 150 million people will be seeking higher education. Javaid (2012) notes that as in the case of Afghanistan, human resource development is particularly important for the economic development of low-income countries as itself.

\section{States of Higher Education Currently}

So this section seeks to highlight the current states of tertiary education in the countries under our study. Kenya for instance has experienced massive swelling in its higher education in the past two decades with only 3 university colleges in the 1980s to 68 institutions of higher learning as of 2014 according to Commission for University Education (CUE) (www.cue.or.ke). The number of students in Kenya's universities has soared up by $28 \%$ in 2014 compared to 2013. The latest Kenyan government data shows that both public and private 
universities in Kenya combined enrolled 443,783 students in 2014. This is a clear comparison to 361,379 students in 2013 and is more than double the enrollment from 2012 (MoE, 2014). The recent increase in demand for higher education can be attributed to the knowledge yearning society. These figures right here are clear indications that expansion is in the process of taking place. It is further reiterated that society requires higher levels of skills and qualifications to fill highly leveled jobs (O'Neill et al., 2004) explaining the recent surge in numbers of students wanting to acquire higher education. Lebanon boasts of 42 higher education institutions (HEIs) as of 2014 as per available data which are fully supervised by the general directorate for higher education, up from only three HEIs by the 1940s, with only one public university while the rest of the 41 institutions are private HEIs (Bemosal, 2014). The student enrolment at the higher education institutions stood at 195,000 according to data for the academic year 2011/12. An evaluation carried out in 2010 by the directorate general for higher education (DGHE) showed that 33 new branches had been opened by different higher education institutions (EACEA, 2012). This is clear evidence of the massive expansion taking place in the higher education institutions in Lebanon. The educational history of the Sultanate of Oman has undergone rapid and extensive development, by 1970 there was no college or university (Al Bandary, 2005; Al Shmeli, 2009), by 2012 there were more than 62 higher education institutions run by private and public sector offering various programs. Higher education sector in Oman has grown and made extensive and significant development in the last decade. There is heavy investment to improve the education infrastructure, provide increased education opportunities with focus on women education to ensure equality and equity (Baporikar \& Shah, 2012) thus a clear indication of the extensive expansion is taking place.

\section{Progress Indicators}

This section clearly isolates the indicators we have chosen to analyze the rate of progress of massification in these countries.

\subsection{Gross Enrollment Ratio}

Gross Enrollment Ratio (GER) or Gross Enrollment Index (GEI) is a statistical measure used in the education sector and by the UN in its Education Index to determine the number of students enrolled in the education sector at several different grade levels. The United Nations Educational, Scientific and Cultural Organization (UNESCO), describes "Gross Enrollment Ratio" as the total enrollment within a country "in a specific level of education, regardless of age, expressed as a percentage of the population in the official age group corresponding to this level of education".

Lebanon as we had mentioned earlier boasts of 42 Higher Education Institutions (HEIs) as of 2014 as per available data which are fully supervised by the General directorate for higher education. Lebanon's enrolment rate in tertiary education comes second in the MENA region with $48 \%$ according to UNESCO Institute of statistics as of 2013, compared to an average of $33.936 \%$ in the MENA region. Saudi Arabia tops the ranks in the MENA region with $58 \%$ gross enrollment rate, mainly due to many reforms made by the government. During the past years, the tertiary education system in Saudi Arabia has introduced new programs and established more universities and technical schools (Bemosal, 2014). This being said, according to Bemasol, enrolment growth in Lebanon has been quite sluggish at 1.46\% between the years 2000-2012 as compared to Saudi Arabia's 6.44\% growth during the same time period. Nonetheless as Figure 1 indicates a constant growth over the years we can't help but question why Lebanon hasn't been able to meet the $50 \%$ enrollment yet. This sluggish growth can be attributed due to the fact that Lebanon has limited public higher education, with only one public university which is strained with not only poor infrastructure but also its geographical distribution doesn't make the situation any better. The financial constraint phenomenon where high and increasing tuition fees have been experienced can also be one of the reasons that can be attributed to the slugged enrollment. Bemosal (2014) notes that the quality of higher education in Lebanon experiences slowed progress because of the absence of a skilled academic body. This is can be caused by the fact that teachers earn low pay wages and encouragements offered are way below par to increase motivation. 


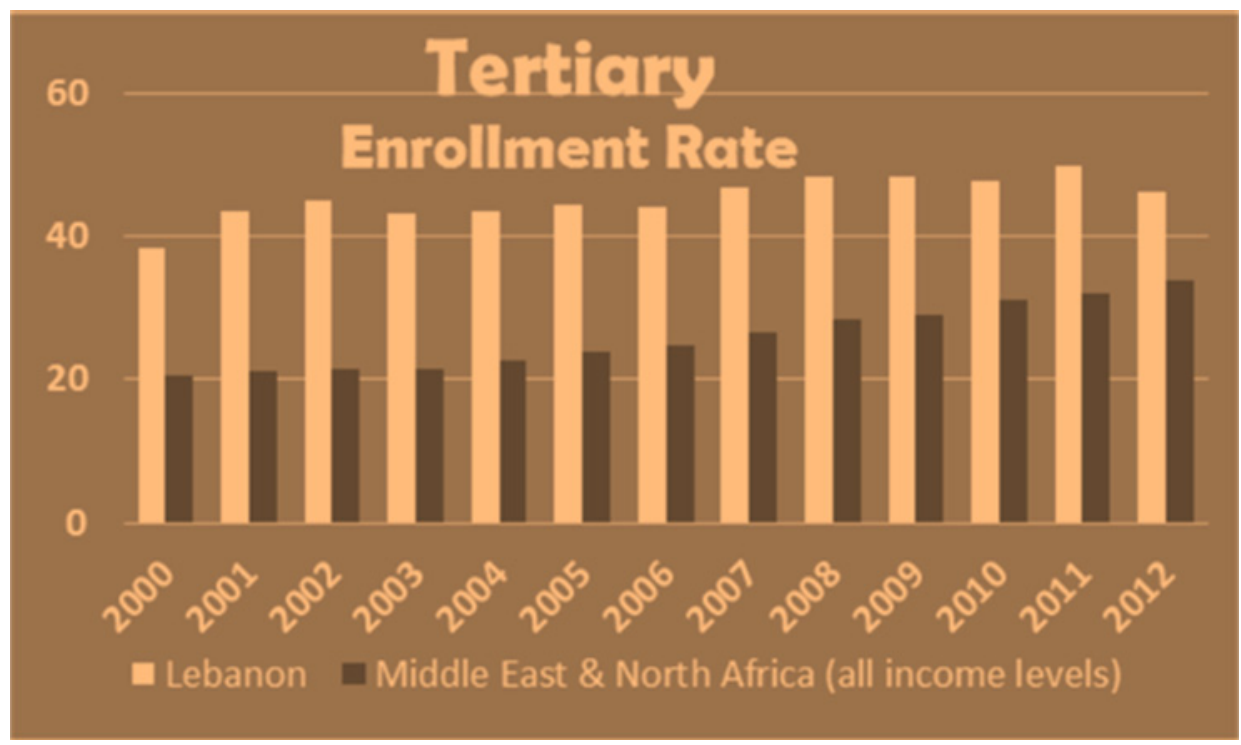

Figure 1. Tertiary enrollment in Lebanon and MENA region for the years 2000-2012

Source: World Bank data, Center for Education and Development, Bemo Research as Adopted from Bemasol 2014.

It can clearly be noted according to (EACEA, 2012) that Lebanon has been able to maintain higher enrollments in their tertiary institutions since Lebanese universities can be seen to be managed quite well. For universities to be legalized in Lebanon, the said universities must be seen to have established a sort of "university institute of technology". Also there exists a committee that is mainly for evaluation, recognition and equivalence of diplomas. Quality of higher education seems to be put at a higher pedestal. Nahas (2009) states that education at the Lebanese University which is the only public university is almost free and affordable fee exemptions are also based on the number of students and social considerations. Some exemptions can be offered to students carrying out some work inside the university; these characteristics therefore go a long way in attracting huge numbers of the Lebanese population into attending higher education (EACEA, 2012).

Oman registered a GER of $21.1 \%$ as of 2008 and has experienced an immense progress of $7.5 \%$ in the GER bringing it to $28 \%$ as of 2013 (as per available UIS data). This progress can be attributed to the fact that Oman has invested heavily in ensuring their higher education is up to standard by importing curricula from western countries, recruitment of native English teachers and recruitment of qualified and experienced faculty. There is intensive investment to improve the education sector infrastructure, provide more and varied education opportunities with focus on women access to higher education to ensure equality and equity (Baporikar \& Shah, 2012). Oman has seen increased enrollment therefore due to the increase in access to more women and with each year has seen increased demand for higher education thus more people enrolling themselves for this heavily craved for commodity. At this point we notice that despite all these efforts towards massification, Oman still hasn't been able to achieve the 50\% enrollment rate according to Trow, so why is this so? Al Balushi (2012) notes that one of the challenges affecting higher education institutions in Oman is the lack of effective leadership of tertiary institutions; strong academic leadership is paramount for effective running of tertiary institutions.

Of the three countries under our scope of study, Kenya seems to be one that records extremely low enrollment. It recorded a GER of $2.966 \%$ of 2005 and experienced an increase of $1.084 \%$ to be at $4.05 \%$ as of 2009 (as per available UIS data). It is very important to note that there is existing progress that is quite impossible to ignore, be that as it may the progress is quite slow and the enrollment rate is nowhere near achieving the $50 \%$ mark. At this point our very paramount question should be to understand why Kenya experiences such lag at this day and age. What exactly is hampering Kenya from achieving not only massification but successful massification of its higher education? The higher education sector of Kenya recently was faced with a series of budget cuts as, the government cut funding by $6 \%$ for the fiscal year, adjusting its higher education budget to US\$588 million as compared to the US\$627.2 million allotted in 2014/15. This is a major challenge as now universities will have to look for other sources to sustain their activities. As if that is not enough, universities were also challenged by the directive from Kenya's Commission for University Education (CUE) to stop offering diploma and certificate courses by July 2015. These courses used to be subsistent sources of income for universities. These cuts may be 
felt by the students as universities may in turn increase costs to cover up for the said cuts. Nyangau (2014) summarizes other challenges affecting Kenya's rapid expansion of its tertiary institutions include issues of "Overcrowding; ever-growing demand; erosion of the non-university sub-sector due to acquisitions and takeovers by public universities in search of space; insufficient/declining public funding; curricula that are not responsive to modern-day needs of the labor market; declining quality; lack of basic laboratory supplies and equipment; crumbling infrastructure; poorly equipped/stocked libraries; poor governance and rigid management structures". The extreme tragic attacks on Kenyan students in 2014 at Garissa University by Al-Shabaab militants focused the globe's attention on Kenya, and to the threats Kenyan students face in some regions if they pursue higher education. They also highlighted the huge divides in the country between certain regions with the northeast region having (in some cases) more trade and ethnic ties to Somalia, as well as sub-standard government services, including education. Despite the fact that demand for higher education is on the rise yearly, the progress of massification is slowed down even more due to such issues of security and marginalization of some students in remote areas of Kenya making the enrollment process to lag behind. According to Tamilenthi and Junior (2011) argue that, in a case for Tanzania, which is Kenya's neighbor also experience low enrollments can be attributed to the fact that, higher education enrollment fees can be said to be too high with very little financial assistance from the government, even fees for the lower technical universities are viewed to be extremely high for the common citizen to afford. These financial constraints can be one of the many reasons as to why enrollments are at an all-time low.

Table 2. GER for developing and developed countries in the year 2009-2013

\begin{tabular}{ccc}
\hline YEAR & DEVELOPED COUNTRIES & DEVELOPING COUNTRIES \\
\hline 2009 & $71.10 \%$ & $21.0 \%$ \\
2010 & $73.92 \%$ & $22.40 \%$ \\
2011 & $75.5 \%$ & $24.20 \%$ \\
2012 & $75.5 \%$ & $25.70 \%$ \\
2013 & $74.14 \%$ & $26.60 \%$ \\
\hline
\end{tabular}

Source: UIS data. Data extracted on 22 Mar 2016 07:18 UTC (GMT) from UIS.Stat.

Table 2 is a vivid representation of the Gross Enrollment Rate (GER) variations in both developing and developed countries. The table clearly displays developing countries to have progressed extensively with a higher GER which is clearly way above Trow's 50\% mark, they can actually be said to have achieved a massified tertiary education system as compared to developing countries which report a way very low GER. This is so because developed countries can be said to have a stable higher education system where the masses are well versed with the needs and necessity of higher education thus resulting to higher enrollments. Developed countries also can be said to have very stable and advanced economies that need employees who are well trained to ensure the economy maintains its stability, therefore the governments tend to advocate for more and highly trained employees, thus to this end, more enrollments tend to be reported. Developing countries on the other hand can be said to have slowed economies and there may be less emphasis on the importance of higher education in cases like the sub-Saharan Africa may as well report very low enrollments more so due to the lack of the citizens in these countries being unable to access the said higher education. Developing countries tend to be ailed by issues like poverty and ailments such as Hiv/Aids making access to higher education is in the least of their concerns.

Table 3. GER for UNESCO institute of statistics regions in the year 2009-2013

\begin{tabular}{lll}
\hline YEAR & ARAB STATES & SUB-SAHARAN AFRICA \\
\hline 2009 & $24.80 \%$ & $7.18 \%$ \\
2010 & $25.50 \%$ & $7.65 \%$ \\
2011 & $25.20 \%$ & $7.90 \%$ \\
2012 & $26.60 \%$ & $8.00 \%$ \\
2013 & $28.12 \%$ & $8.18 \%$ \\
\hline
\end{tabular}

Source: UIS data. Data extracted on 22 Mar 2016 07:18 UTC (GMT) from UIS.Stat. 
Table 3 shows the GER for regions under UNESCO Institute of Statistics (UIS). It can clearly be noted that between Arab states and Sub-Saharan Africa states, the Arab states are seen to be doing way better as compared to the Sub-Saharan Africa which records way below par in terms of their enrollment. These two regions can be said to have slowed enrollment and have not been able to achieve the 50\% Trow mark in higher education simply because they are developing states and they have more crucial jeopardy to deal with and higher education is not given much attention. Needless to say though, due to the recent modernization even these states will begin to record more numbers in their higher education institutions as these states begin to realize that higher education stability is the key driver to ensure any economy success. The three countries under our comparative lens are clear representatives in the developing world whose GER can be seen to be way low as compared to their developed counterparts.

\subsection{Demographics and Higher Education}

Canete (2012) notes that the influence of population on the dynamics of any nation is very straightforward. In the field of population studies, it has long been recognized that education is strongly related to a broad range of demographic behaviors. As early as 1980, Caldwell who was cited by UN in 2003 reiterated that once a society/nation has achieved "mass education" high levels of fertility would no longer persist or would decrease entirely as more and more people become engrossed in joining higher education and have lesser time on their hands to engage in fertility circles.

Table 4. Total population in thousands of three sampling countries in the year 2009-2013

\begin{tabular}{|c|c|c|c|c|}
\hline YEAR & COUNTRY & LEBANON & OMAN & KENYA \\
\hline 2009 & & 4246.924 & 2663.224 & 39824.730 \\
\hline 2010 & & 4341.092 & 2802.768 & 40909.19 \\
\hline 2011 & & 4478.105 & 3024.774 & 42027.89 \\
\hline 2012 & & 4647.079 & 3314.001 & 43178.14 \\
\hline 2013 & & 4821.971 & 3632.444 & 44353.69 \\
\hline
\end{tabular}

Source: UIS data. Data extracted on 22 Mar 2016 07:18 UTC (GMT) from UIS.Stat.

From Table 4, we can clearly deduce that all the countries have clearly recorded an increase in their population numbers over the past five years (2009-2013). Our concern at this point is to find out the impact that population has on higher education. This increase in population can also be indicated by the increased masses/demand for higher education overly. It is paramount to note however that despite all the countries having recorded soars in their population, Kenya recorded the highest numbers with $44 \mathrm{M}$ as at 2013 as per available UIS data. Increases population means automatically that more and more numbers of students join tertiary institutions. It is important to note that despite these increases in the demand for tertiary education, tertiary institutions remain the same with little expansion of the infrastructures to accommodate the soaring numbers. This in turn has devastating effects on the quality of higher education provided. On the other hand Lebanon and Oman recorded the lowest increases with $4.8 \mathrm{M}$ and 3.6M (Approx.) respectively as at 2013 as per available UIS data. States with the highest population ratios actually recorded the lowest GER, while the states that recorded the lowest population increases recorded the highest GER. This phenomenon can be concluded by Canete (2012) who notes that it is about having enough resources to be able to meet the needs of the swelling numbers of people. Countries with higher populations have limited resources and therefore this puts a strain on the progress of massification. Fewer masses end up in tertiary institutions since the same resource base is co-shared by all members of the society, everybody is affected by the development and many are therefore deprived of their ability to access the very same limited resources. Canete (2012) also notes that among both women and men, an early age at first marriage is more common among those with no education than among their educated peers, thus explaining the fewer enrollments in African countries leading to higher population numbers. Lebanon and Oman can also be said to record higher GER and experience lower numbers in their demographics due to the fact that educating more masses reduces by a huge margin the fertility rate thus more enrollments in tertiary institutions. 


\subsection{International/ Universalization}

UNESCO defines the term "internationally mobile students" to the students who have physically crossed an international border between two countries with the objective to participate in educational activities in the country of destination, where the country of destination of a given student is different from their country of origin. The numbers of students pursuing tertiary education abroad continues to be at an all-time high as institutes of higher education around the world continuously vie for the best of the best as far as international students are concerned. The rise in internationally mobile studentsreflects the intense progress that mass tertiary education is going through. According to UIS data, "in 2013, over 4.1 million students went abroad to study, up from 2 million in 2000, representing $1.8 \%$ of all tertiary enrolments or 2 in 100 students globally". The Table 5 is a representation of the outbound mobility ratios of the 3 countries under scrutiny.

Table 5. Outbound mobility ratios of four sampling countries in different years

\begin{tabular}{cccc}
\hline COUNTRY & \multicolumn{2}{c}{ OUTBOUND MOBILITY RATIO } & \%INCREASE/DECREASE \\
\hline LEBANON & $7.03 \%(2009)$ & $5,21 \%(2013)$ & -1.82 \\
OMAN & $13.41 \%(2009)$ & $14.47 \%(2013)$ & +1.06 \\
KENYA & $12.35 \%(2005)$ & $8.23 \%(2009)$ & -4.12 \\
\hline
\end{tabular}

Source: UIS data. Data extracted on 22 Mar 2016 07:18 UTC (GMT) from UIS.Stat.

Two countries report a reduced ratio of students studyingbroad, Kenya and Lebanon at $4.12 \%$ and $1.82 \%$ respectively. Oman on the other hand, experienced an increase in the numbers of students going to study abroad with an increase of $1.06 \%$. The decreases experienced in the three countries can be used as an indicator of progress meaning that domestic higher education is becoming more attractive and students are to students are opting to study more at home than abroad. According to a UNESCO report, students from sub-Saharan Africa, can be said to stay closer to home. The latest data indicates that sub-Saharan Africa outbound mobility ratio dropped from $6 \%$ in to $4 \%$, this is a clear indication that domestic higher education systems are progressing and expanding extensively causing more students to study home than abroad. It is also paramount to note that higher education abroad may be quite expensive making it impossible for students from these countries unable to afford it, thus they opt to attend more domestic tertiary institutions that are affordable.

\subsection{Economics/GDP Per Capita and Higher Education}

Investment in education makes an important and very crucial at that a contribution to societies' economic growth and to the economic successes of the individuals. Investment in education secures returns in the form of skilled labor which eventually leads to increased development in the economy of any state and improved quality of life (Yogish, 2006). Alam (2009) notes that Investment in education is not only beneficial to individuals through the reward of income but also is beneficial to the economy as a whole through skilled labor who level competition and increase economic growth of the state. Therefore the GDP per capita can be used as an indication of progress in the massification process of these countries. It is therefore in this light that the higher education sector of all nations should pay extremely close attention to higher education. Higher education to this end can be said to be the backbone of all economies. The Table 6 shows the GDP per capita in constant 2005 US dollars of the three countries.

Table 6. GDP per capita in constant 2005 US dollars

\begin{tabular}{cc}
\hline GDP PER CAPITA( CONSTANT 2005 US \$) \\
\hline LEBANON & 7256.5 \\
OMAN & 11004.0 \\
KENYA & 658.7 \\
\hline
\end{tabular}

Source: UIS data. Data extracted on 22 Mar 2016 07:18 UTC (GMT) from UIS.Stat.

Kenya can be noted to have equally very low GDP as compared to both Oman and Lebanon. The GDP per capita of any economy can be said to be directly proportional to its enrollment in tertiary institutions. Higher 
enrollments result to highly skilled labor that in turn stimulates the GDP of the economy higher. Kenya records lower GDP can also be seen to have equally lower enrollments in its tertiary institutions, while Oman and Lebanon that have a higher GDP can be seen to record higher enrollments. It is safe hereby to conclude that any country's GDP is a reflection of the state of the higher education there in. This is can be explained by the fact that they have higher enrollments, Lebanon and Oman tend to produce more skilled labor that can handle the country's economy thus pushing it to higher levels resulting in higher records of GDP.

\section{Conclusion}

The issue of progress is one that is very important in today's world. Analysis of progress enables us to understand the place and status of tertiary education. Analysis of progress also enables us to understand further the crisis and problems ailing higher education and thus being able to take appropriate steps towards ensuring successful massification progress. This papers purpose was to analyze the progress that the three countries have made towards the process of massification in their higher education institutions. It is without a doubt agreeable to say that progress is taking place though at different paces for different reasons in these countries. We have pegged down 4 core indicators that can be used to mirror the states of massification in these countries. The demographics, internationalization/universalization and GDP per capita (economics) can be said to be directly related to the GER in higher/tertiary education systems/institutions. This paper has further very clearly at that identified that Lebanon and Oman are on the fore front as far as the progress of massification is concerned, while Kenya is seemingly lagging behind tremendously due to challenges of access, quality and infrastructure. It is crucially paramount at this point to note that the need/demand for education will only continue to surge further even as these countries gear themselves towards achieving successful massification, with each passing time, the question at hand rather would be as to whether these institutions will maintain their stability as more and more masses yearn for higher education. Will these institutions maintain their quality? As these countries gear towards successful massification and eventually universalization, these challenges must be dealt with first and fast to ensure these institutions serve their academic function effectively.

\section{References}

Al Balushi, A. (2012). Leadership of private universities and colleges in the Sultanate of Oman. (Doctoral Thesis, p. 290). University of Southampton, School of Management.

Al Bandary, M. S. (2005). Meeting the challenges: The development of quality assurance in Oman's Colleges of Education. Higher Education, 50(2), 181-195. http://dx.doi.org/10.1007/s10734-004-6348-y

Al Shmeli, H. (2009). Higher Education in the Sultanate of Oman: Planning in Context of Globalization. IIEP Policy Forum.

Alam, G. M. (2009). Can governance and regulatory control ensure private higher education as business or public goods in Bangladesh? African Journal of business management, 3(12), 890. Retrieved from http://www.academicjournals.org/SRE/93C2C0019016

Baporikar, N., \& Shah, A. (2012). Quality of higher education in 21 st century - A case of Oman. Retrieved from http://www.wjeis.org//2146-7463

Bemo, B. (2014). Education in Lebanon. BEMO industry report.

Canete, L. (2011). Reviewing the effects of population growth on basic education development, CNU. Journal of Higher Education, 5. Retrieved from http:// www.academia.edu/1193825/

Cave, M., \& Weale, M. (1992). The assessment: Higher Education: The state of play. Oxford Review of Economic Policy, 8(2), 1-17. http://dx.doi.org/10.1093/oxrep/8.2.1

Chen, D. Y. (2004). Chinas Mass Higher Education: Problem, Analysis and solutions. Asia Pacific Education Review, 5(1), 23-33. http://dx.doi.org/10.1007/BF03026276

Claire, K. A. L. (1988). Higher education access and participation: Political dependency and student choice. $\begin{array}{llll}\text { International Journal of Educational Research, 12(4), 375-393. } & \end{array}$ http://dx.doi.org/10.1016/0883-0355(88)90032-8

Fasih, T. (2008). Linking education policy to labor market outcomes. World Bank Publications. http://dx.doi.org/10.1596/978-0-8213-7509-9

Hanushek, E., \& Woessmann, L. (2008). The Role of Cognitive Skills in Economic Development. Journal of Economic Literature, American Economic Association, 46(3), 607-618. http://dx.doi.org/10.1257/jel.46.3.607 
Hanushesk, E., \& Welch, F. (2006). Handbook of the Economics of Education. Elsevier Science and Technology, 1. Retrieved from https://www.elsevier.com/10.1016/s1574-0692(06)010075

Higher Education in Lebanon, Education, Audiovisual and Culture Executive 10 Agency (2012). State of Play of the Bologna Process in the Tempus Partner Countries (2012), A Tempus Study. EACEA, Brussels. Retrieved from http://eacea.ec.europa.eu/tempus/

http://china-trade-research.hktdc.com/business-news/article/One-Belt-One-Road/The-Belt-and-Road-Initiative/o bor/en/1/1X000000/1X0A36B7.htm

http://www.UNESCO.org/new/en/education

http://www.worldbank.org/depweb/English/beyond/global/glossary.html

Javaid, M. K. (2012). Education in Afghanistan: Private Higher Education Sector Contribution. Retrieved from http://conference.pixel-online.net/FOE/files/foe/ed0004/FP/0499-SOE527-FP-FOE4

John, B., Fransisco, O., \& Ramirez, J. W. M. (1985). Comparative Education Review, 29(2), 145-170. http://dx.doi.org/10.1086/446504

Kenya. (2014). Ministry of Education science and technology. Retrieved from http://www.education.go.ke

Kinyanjui, K. (2007). The transformation of higher education in Kenya: Challenges and opportunities. Retrieved from http://www.dpmf.org/images/12.pdf

Nyangau, J. Z. (2014). Higher Education as an Instrument of Economic Growth in Kenya. Forum for International Research in Education, 1(1). Retrieved from http://preserve.lehigh.edu/fire/vol1/iss 1/3

O’Neill, K. S., \& O’Donoghue, J. (2004). Implementing e-learning programs for higher education: A review of literature, 3(1), 313-323. Retrieved from https://www.researchgate.net/publication/220590692

Patrinos, H., \& Psacharopoulos, G. (2011). Education: Past, Present and Future Global Challenges. In Policy Research Working Paper Series 5616. The World Bank, Washington DC. http://dx.doi.org/10.1596/1813-9450-5616

Tamilenthi, S., \& Junior, L. E. (2011). The barriers of higher education in the African countries of Zambia and Tanzania. Archives of Applied Science Research, 3(4), 169-178. Retrieved from http://scholarsresearchlibrary.com/archive.html

Trow, M. (1969). Elite and Popular Functions in American Higher Education. In W. R. Niblett (Ed.), Higher Education: Demand and Response (pp. 181-201). London: Tavistock Publications.

Trow, M. (1970). Reflections on the Transition from Mass to Universal Higher Education. Daedalus, 99, 1-42. Retrieved from http://escholarship.org/uc/item/96p3s213

Trow, M. (1974). Problems in the Transition from Elite to Mass Higher Education. In Future Structures of Post-Secondary Education: Policies for Higher Education (pp. 55-101). Paris: Organization for Economic Cooperation and Development. Retrieved from http://files.eric.ed.gov/fulltext/ED091983.pdf

Trow, M. (1979). Elite and Mass Higher Education: American Models and European Realities. In Research into Higher Education: Processes and Structures (pp. 44-53). Stockholm: National Board of Universities and Colleges.

UNESCO Institute for Statistics Database (UIS) (2016).

United Nations. (2003). Population, Education and Development. UN Department of Economic and Social Affairs, population Division, New York. Retrieved from http://www.un.org/esa/population/publications/concise2003/Concisereport2003.pdf

Wesley, D. (2002). A critical analysis on the evolution of e-learning. International Journal on E-learning, 1(4), 41-48. Retrieved from http://www.editlib.org/p/9168

Women's Access to Higher Education in Afghanistan. (2011). Retrieved from http://www.epd-afg.org

World Bank. (2012b). Putting Higher Education to Work: Skills and Research for Growth in East Asia. Washington DC. Retrieved from http://www.worldbank.org/10.1596/978-0-8213-8490-9

Yogish, S. N. (2006). Education and Economic Development. Indian Journal of Social Development, 6(2), 255-270. 


\section{Copyrights}

Copyright for this article is retained by the author(s), with first publication rights granted to the journal.

This is an open-access article distributed under the terms and conditions of the Creative Commons Attribution license (http://creativecommons.org/licenses/by/4.0/). 